\title{
The short-term effect of an immunosuppressive treatment on CSF myelin basic protein in chronic progressive multiple sclerosis
}

\author{
K J B LAMERS, * B M J UITDEHAAG, * O R HOMMES, * W DOESBURG, $\dagger$ \\ R A WEVERS, * W J A v GEEL*
}

From the Institute of Neurology* and Department of Statistical Consultation, $\dagger$ Radboud Hospital, University of Nijmegen, The Netherlands

SUMMARY CSF levels of myelin basic protein (MBP) and intrathecally produced CSF IgG (de novo IgG) were measured in 11 chronic progressive multiple sclerosis patients with a deteriorating course of the disease for at least 6 months preceding observation and a reference group of 17 neurological patients suffering from disc herniation. In the multiple sclerosis patients, CSF levels were determined just before and once in the period 3 to 10 weeks after the start of an immunosuppressive treatment with cyclophosphamide and prednisone. For multiple sclerosis patients the CSF MBP levels before treatment were significantly higher than for controls. The CSF MBP levels after the treatment were nearly all within the control range. The abnormal high concentration of intrathecally produced CSF IgG (de novo IgG) in multiple sclerosis patients was reduced after treatment. A correlation between CSF MBP and CSF de novo IgG in multiple sclerosis patients could not be demonstrated. If CSF MBP is an indicator of the (activity of) myelin breakdown in the brain, it can be concluded that an intensive immunosuppressive treatment in combination with prednisone has, at least, a short-term, beneficial effect on the amount of demyelinisation and possibly on the disease activity.

Increased levels of myelin basic protein (MBP) or fragments of it in cerebrospinal fluid (CSF) have regularly been observed in patients with neurological diseases such as head injury and stroke. ${ }^{1-8}$ The measurement of MBP in CSF has appeared to be a useful indicator of tissue damage. Furthermore, recent studies in multiple sclerosis patients have also shown increased MBP levels in CSF, especially after an acute exacerbation of the disease. ${ }^{349-12}$ From these studies one may conclude that the amount of CSF MBP in exacerbating forms of multiple sclerosis is higher (1) during the first week after onset of an attack, ${ }^{21}$ (2) in polysymptomatic attacks compared with monosymptomatic attacks, ${ }^{10}$ (3) in severe attacks with complete paralysis and (4) during exacerbations with the presence of new signs and symptoms. In chronic progressive forms of multiple Address for reprint requests: Dr K J B Lamers, Institute of Neurology, St Radboud University Hospital, PO Box 9101, 6500 HB Nijmegen, The Netherlands.

Received 4 December 1987 and in revised form 28 April 1988. Accepted 4 May 1988 sclerosis increased MBP levels in CSF are regularly found, but the percentages of abnormalities and the amount of MBP in CSF are generally lower than during an acute phase of the disease process in exacerbating forms. ${ }^{341012}$ If the CSF MBP level can be used as an indicator of demyelinisation and/or disease activity in patients with multiple sclerosis, measurements of CSF MBP before and after therapy might give information about the effect of the therapy on the myelin degradation in the CNS.

The purpose of our investigation was to study the possible effect of an immunosuppressive treatment on the level of CSF MBP in 11 chronic progressive multiple sclerosis patients with a deteriorating form of the disease. The effect of treatment on intracerebrally produced IgG and the relation between IgG and MBP were also studied.

Subjects and methods

Subjects

The multiple sclerosis patients $(\mathrm{n}=11$, age $20-36 \mathrm{yr})$ were 
definite multiple sclerosis patients with a chronic progressive course of the disease. These patients had a continuous deterioration of clinical symptoms for at least 6 months before treatment. They received an intensive immunosuppressive treatment consisting of a daily dose of $400 \mathrm{mg}$ cyclophosphamide and $100 \mathrm{mg}$ prednisone, with a total dose of $8 \mathrm{~g}$ cyclophosphamide. ${ }^{13}$ The duration of treatment was between 4 and 5 weeks. Just before starting treatment and once 3-10 weeks later blood and CSF samples were taken. The multiple sclerosis patients had never received any immunosuppressive treatment before. As reference a control group of neurological patients ( $n=17$, age 24-72 yrs) suffering from disc herniation in whom no signs of demyelinisation could be observed was used.

\section{Methods}

$M B P$ assay. MBP was determined according to the instructions of the manufacturer, Diagnostic Systems Laboratories, Webster Texas USA cat. nr. 1500, using a double antibody RIA kit containing human myelin basic protein (whole molecule) as antigen and rabbit antihuman MBP as antiserum. Goat anti-rabbit gamma globulin was used as MBP precipitation reagent. Human MBP $\left(\mathrm{J}^{125} 2 \mu \mathrm{Ci} /\right.$ vial $)$ was included in the test kit.

IgG/Albumin assay. IgG and albumin were measured in unconcentrated CSF and diluted serum (1:400). Sheep antihuman IgG (Boehringer, Mannheim) and rabbit antihuman albumin (Behringwerke, Marburg) were used in the assay.

$$
\begin{array}{ll}
\text { Q Alb } & \text { CSF Alb/serum Alb } \\
\text { Q IgG } & \text { CSF IgG/serum IgG }
\end{array}
$$$$
\text { IgG Index }=\mathrm{Q} \text { IgG/Q Alb }
$$

The calculation of CSF IgG, synthesised in the central nervous system (de novo CSF IgG), was performed according to the formula of Reiber ${ }^{14}$ with minor modifications.

Statistics. For each of the biochemical variables we present the median value and the range of the observed levels. For the multiple sclerosis patients the statistical comparison of the pre and post treatment values was by means of the Wilcoxon test for the paired case. The statistical comparison between different patient groups was by the Wilcoxon test for the unpaired case. The results of a comparison were considered to be significant if its corresponding $p$ value was smaller or equal to 0.05 . The statistical dependence between two variables was evaluated by means of Kendall's test for rank correlation.

\section{Results}

\section{$M B P$}

The individual results of the CSF MBP determination are shown in the fig. The median value and the range of CSF MBP are given in the table. Within the group of 11 multiple sclerosis patients nine showed an elevated CSF MBP level (higher than the estimate of the 95 th centile for the reference group $=2.3 \mu \mathrm{g} / \mathrm{l}$ ) before treatment. After treatment only three patients had increased levels of CSF MBP.

For multiple sclerosis patients the CSF MBP levels were significantly $(p=0.01)$ lower after treatment (median $1.7 \mu \mathrm{g} / \mathrm{l}$ ) than before treatment (median 4.2

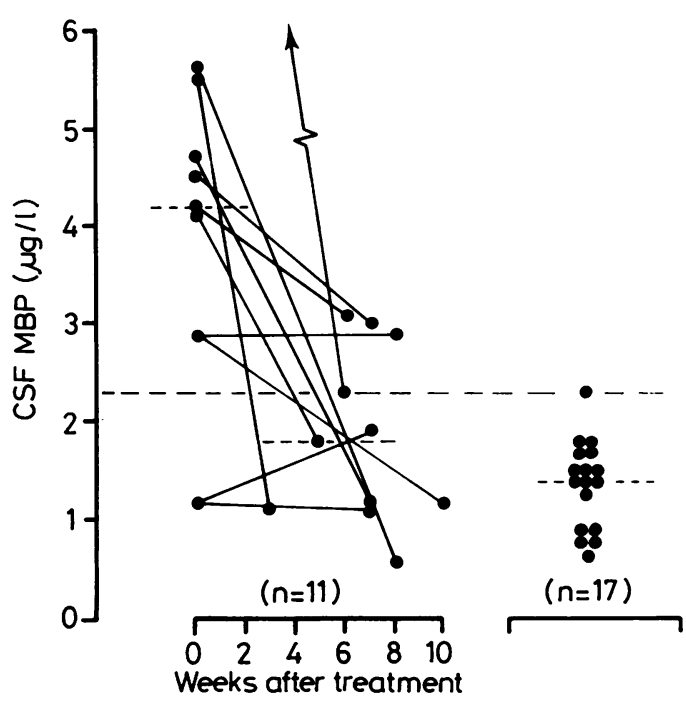

MS group $1 \quad$ Controls

Fig CSF MBP values in chronic progressive multiple sclerosis patients with a deteriorating course before and after treatment and controls.

\begin{tabular}{|c|c|c|c|c|}
\hline Patients & Number & $\begin{array}{l}\text { Before treatment } \\
M B P \text { in CSF }(\mu g / l) \\
\text { Median Range }\end{array}$ & $\begin{array}{l}\text { After treatment } \\
M B P \text { in } C S F(\mu g / l) \\
\text { Median range }\end{array}$ & $\begin{array}{l}\text { Comparison } \\
\text { p-value }\end{array}$ \\
\hline \multirow[t]{2}{*}{$\begin{array}{l}\text { Multiple sclerosis group } \\
\text { Controls }\end{array}$} & $\begin{array}{l}11 \\
17\end{array}$ & $\begin{array}{l}4 \cdot 2(1 \cdot 2-15) \\
1 \cdot 4(0 \cdot 7-2 \cdot 3)\end{array}$ & $1 \cdot 7(0 \cdot 6-3 \cdot 1)$ & 0.01 \\
\hline & & $\begin{array}{l}\text { de novo CSF IgG } \\
(\mathrm{mg} / \mathrm{l})\end{array}$ & $\begin{array}{l}\text { de novo CSF IgG } \\
(\mathrm{mg} / \mathrm{l})\end{array}$ & \\
\hline \multirow[t]{2}{*}{ Multiple sclerosis group } & 11 & $43(16-100)$ & $19(0-70)$ & 0.004 \\
\hline & & $\operatorname{Ig} G$ index & IgG index & \\
\hline Multiple sclerosis group & 11 & $1.25(0.93-3.21)$ & $1.02(0 \cdot 76-1.91)$ & 0.002 \\
\hline
\end{tabular}

Table Median value and range for CSF MBP, de novo IgG and IgG index in multiple sclerosis patients and controls 
$\mu \mathrm{g} / \mathrm{l})$. The MBP level for multiple sclerosis patients before treatment was significantly higher than for controls ( $p=0.001$ ), while the MBP level of multiple sclerosis patients after treatment was not significantly different from that of controls $(p=0 \cdot 29)$. From these results it can be concluded that the abnormal CSF MBP levels of "active" chronic multiple sclerosis patients are decreased to the reference limits 3-10 weeks after the start of the treatment.

\section{De novo CSF IgG}

With respect to the de novo CSF IgG, before treatment all multiple sclerosis patients had abnormal IgG indices (higher than 0.59 in our laboratory) and abnormal IgG production (median $43 \mathrm{mg} / \mathrm{l}$ ).

After treatment, the de novo CSF IgG value (median $19 \mathrm{mg} / \mathrm{l})$ was significantly $(\mathrm{p}=0.004)$ reduced, but changes in oligoclonal pattern were not observed after treatment and an abnormal IgG production could always be observed.

\section{Relation between MBP level and de novo IgG level in CSF}

We could not demonstrate any significant correlation between MBP and CSF de novo IgG or IgG index in the multiple sclerosis group.

\section{Discussion}

Cerebrospinal fluid MBP levels are probably an indication of the degree of demyelinisation in multiple sclerosis patients and its quantitation might be used to monitor disease activity and to study the effect of putative therapy. The actual level of CSF MBP reflects the amount of tissue undergoing demyelination, the actual rate of myelin breakdown and the location of the lesion with respect to the lumbar space. $^{4}$

In exacerbating forms of multiple sclerosis it has been emphasised that CSF MBP levels mostly return to normal values 2 to 4 weeks after acute attacks. ${ }^{2-49}$ This, however, is not the case in patients in whom clinical deterioration still remains after recovery. ${ }^{411}$

In chronic progressive forms of multiple sclerosis, elevated CSF MBP levels are found in about $50 \%$ of the patients.

Elevated MBP levels are only found in chronic progressive multiple sclerosis patients with a significantly deteriorating course. ${ }^{3412}$ The results of our study confirm abnormal CSF MBP values in chronic deteriorating multiple sclerosis patients.

After intensive immunosuppressive treatment CSF MBP levels normalise in nearly all patients. The CSF MBP level in the multiple sclerosis patients, averaged 6 weeks after treatment, can statistically not be distinguished from controls. If CSF MBP is an indicator of the (activity of) myelin breakdown in the brain, one can conclude that an intensive immunosuppressive $\mathbb{Q}$ treatment in combination with prednisone has, at least a short-term, beneficial effect on demyelinisation and possibly on the disease activity. The question can 6 be asked whether the effect of treatment on disease $T$ activity can be measured by its effect on CSF MBP levels.

With respect to the IgG production, this study shows that all multiple sclerosis patients showed intrathecally produced CSF IgG before treatment and a clear reduction of the abnormal IgG amount after $\bar{O}$ treatment. Although treatment has a beneficial effect on the amount of intrathecal IgG production, the abnormal IgG production and the oligoclonal pattern remain.

Finally, the absence of a correlation between CSF MBP level and IgG production might suggest that demyelinisation and (local) immunological activity are not related. However, a relationship between disease activity and cerebral IgG production is rarely found in multiple sclerosis studies.

\section{References}

1 Mukherjee A, Vogt RF, Scott Linthicum D. Mea surement of myelin basic protein by radio immunoassay in closed head trauma, multiple sclerosi and other neurological disease. Clin Biochen 1985;18:304-7.

2 Whitaker JN, Lisak RP, Bashir RM, et al. Immu noreactive myelin basic protein in the cerebrospinats fluid in neurological disorders. Ann Neurot 1980;7:58-64.

3 Biber A, Englert D, Dommasch D, Hempel K. Myelin basic protein in cerebrospinal fluid of patients with multiple sclerosis and other neurological diseases. $J$ Neurol 1981;8:25-31.

4 Cohen SR, Brooks BR, Herndon RM. McKhann GM. A diagnostic index of active demyelination: $J$ Neurol 1981;225:231-6.

5 Gerson B, Cohen SR, Gerson IM, Guest GH. Myelin basic protein, oligoclonal bands, and IgG in cerebrospinal fluid as indicators of multiple sclerosis. Clin Chem 1981;27:1974-7.

6 Kohlschutter A. Myelin Basic Protein in cerebrospinal fluid from children. Eur J Pediatr 1978;127:155-61.

7 Jacque C, Delasalle A, Rancurel GE, Raoul M, Lesourd B, Legrand JC. Relationship between its presence and the occurrence of a destructive process in the brains of encephalitic patients. Arch Neurol 1982;39:557-60.

8 Warren KG, Catz I, McPherson RA, CSF Myelin Basic Protein levels in acute optic neuritis and multiple sclerosis. Can J Neurol Sci 1983;10:235-8.

9 Thomson AJ, Brazil JA, Feighery C, et al. CSF Myelin Basic Protein in multiple sclerosis. Acta Neurol Scand 1985;72:577-85.

10 McPherson TA, Catz I. A double antibody radio- 
immunoassay for Myelin Basic Protein in cerebrospinal fluid. Clin Biochem 1985;18:297-9.

11 Whitaker JN. Myelin encephalitogenic protein fragments in cerebrospinal fluid of persons with multiple sclerosis. Neurology 1977;27:911-20.

12 Martin-Moudiere C, Jacque C, Delasalle A, Cesaro P, Carydakis C, Denis Degos J. Cerebrospinal myelin basic protein in multiple sclerosis. Arch Neurol 1987;44:276-8.
13 Hommes OR, Lamers KJB, Reekers P. Effect of intensive immunosuppressive on the course of chronic progressive multiple sclerosis. J Neurol 1980; 223:177-90.

14 Reiber $H$. The discrimination between different bloodCSF barrier dysfunctions and inflammatory reactions of the CNS by a recent evaluation graph for the protein profile of cerebrospinal fluid. $J$ Neurol 1980;224:89-99. 